\title{
I Vorbemerkung: Der „bessere Teil der Menschheit“
}

Eine Idee, eine Kunstform, keimt nie in der Menge. Die Idee, das Bild keimen in dem Einzelnen, der über der Menge steht, und sie an sich zieht. - Die Initiative geht immer von dem großen Menschen aus, nie von der Menge. Die Elite bestimmt alles. (Georg Brandes 1898)

Der dänische Philosoph, Literat und Literaturkritiker Georg Brandes ${ }^{1}$ trifft mit seiner Feststellung den Kern, der den Reiz und die Relevanz der Elitenforschung letztlich ausmacht: „Die Elite bestimmt alles.“ Dies ist zweifelsohne eine äußerst provokante Äußerung, die aber in der Geschichte wie auch heute durchaus ihre Entsprechung findet. Politische und gesellschaftliche Prozesse sind selten von einer breiten anonymen Masse bestimmt. Auch in demokratischen Gesellschaften, in welchen das Wort Elite schon fast eine negative Konnotation annimmt, sind es letzten Endes die (Funktions-)Eliten, welche die gesellschaftliche und politische Führung behaupten und, wie Brandes durchaus richtig erkennt, die Menge an sich ziehen.

Der zeitliche Abstand von über 1.500 Jahren lässt uns die spätantiken Senatoren Roms sehr fern erscheinen. Es ist aber vor allem ihr Verdienst als Bewahrer der antiken Kulturgüter, des Wissens und der Ideen, dass ein beträchtlicher Teil des ,antiken Geistes“ über das Mittelalter hinweg erhalten blieb. In der ausgehenden Antike, die nicht unbegründet als eine Zeit der Transformation, der Veränderungen und Umbrüche $^{2}$, aber auch der Krisen und des gewaltsamen Niedergangs ${ }^{3}$ aufgefasst wird, werden die senatorischen Eliten Roms und des Westens zugleich zu Bewahrern ${ }^{4}$ und Erneuerern ihrer Welt. Im Besonderen betrifft dies die Christianisierung des Römischen Reiches. Hier nimmt die Senatsaristokratie im 5. Jh. eine entscheidende Mittlerrolle ein, die das klassisch-pagane Erbe mit der christlichen Erneuerung verbindet, so dass letztlich das Christentum selbst zum Erben und Träger römisch-antiken Kulturgutes werden konnte.

Statt die erste Hälfte des 5. Jhs. als eine Zeit aneinander gereihter Katastrophen zu verstehen, können auch die immer noch beachtlichen Kraftreserven, die erstaunliche Vitalität und der gestalterische Wille, welcher dieser Zeit inhärent ist, hervorgehoben werden. Diese Vitalität spiegelt sich in vielen Bereichen des Kulturlebens wider, welches wiederum maßgeblich von der Senatsaristokratie geprägt wurde. Restaurierungsarbeiten, Stiftungen und ebenso Neubauten, insbesondere Kirchen und Platzanlagen, bezeugen eindrucksvoll die Lebenskraft dieser Zeit. Die christliche Bildwelt erreichte ihren ersten Kulminationspunkt, der bis heute eine der wichtigsten Referenzgrundlagen der Sakralkunst und der Imagination der christlichen Weltordnung

1 Geboren 1842 als Morris Cohen in Kopenhagen, gestorben 1927; das Zitat stammt aus Studien und Kritik zur Geschichte von Hippolyte Taine (1898) XIII.

2 Der Transformationsgedanke wurde vor allem seit den späten 1980ern von BROWN und CAMERON vertreten.

3 Diese ältere Position vertreten seit 2005 neuerdings wieder HEATHER und WARD-PERKINS.

4 Hierzu vgl. auch die lobenden Worte Prok. BG. 4,22,5.

Ә OpenAccess. () 2021 Hendrik A. Wagner, publiziert von De Gruyter. (cc) BY-NC-ND Dieses Werk ist lizenziert unter der Creative Commons Attribution-NonCommercial-NoDerivatives 4.0 International Lizenz. 
darstellt. In der Spielgebung werden gerade in der alten Urbs aeterna neue Superlative definiert, die das Vertrauen in die allumfassende und immerwährende Herrschaft Roms weiterhin aufrechterhalten sollten.

Folgen wir dem Gedankengang, den Brandes vorbringt, bis in seine letzte Konsequenz, so ließe sich konstatieren, dass die Elite, wenn sie denn alles bestimmt, auch ihr Überleben und ihr Ende in der Hand hält. In gewisser Weise trifft dies auch auf die stadtrömische Senatsaristokratie zu, insofern sie alles daransetzte, sich und die Welt um sich herum am Leben zu erhalten. In der ersten Hälfte des 5. Jhs. werden die Grundlagen dafür geschaffen, dass die Senatsaristokratie und der Senat noch weitere 150 Jahre überdauern konnten, während dagegen das Kaisertum im Westen erlischt und am Ende auch die weströmischen Heermeister aus der Geschichte verschwinden.

Insofern kann der Senatsaristokratie vieles vorgeworfen werden, auch eigennütziges Handeln, doch nicht ein generelles Desinteresse ${ }^{5}$ an den Belangen des Reiches. Allein schon im Hinblick auf die über das gesamte Imperium ausgreifenden Beziehungen, Patronate und Besitzungen ist dies nur schwer vorstellbar. Wenn überhaupt eine Personengruppe im Reich ,global' denken und agieren konnte und ein Interesse daran haben musste, dass die bestehende Ordnung, auch unabhängig von Kaisern und Heermeistern, erhalten blieb, so war dies die stadtrömische Senatsaristokratie.

Es wurde hierbei zwar immer wieder darauf hingewiesen, dass die Senatsaristokratie, indem sie der Zentralgewalt die knapper werdenden Ressourcen streitig machte, eher eine unrühmliche Rolle gespielt habe. ${ }^{6}$ Dabei wird aber nur selten berücksichtigt, dass die Interessen und Ansichten, wie mit den Herausforderungen umzugehen sei, weit auseinandergingen. Das Fehlen einer entsprechenden politischen Programmatik ${ }^{7}$ ist den senatorischen Häusern Roms und dem Senat dennoch nicht einfach zu unterstellen. Die eigene Selbsterhaltung in der Wahrung der strukturellen Grundlagen der eigenen Macht, der materiellen und finanziellen Basis sowie das Aufrechterhalten der Identität stiftenden Traditionsbilder, insbesondere in Rückbesinnung auf die Urbs aeterna, stellten das senatorische Kerninteresse dar, das sich letztlich auch gegenüber den neuen christlichen Lebensidealen, vor allem christlich-asketischen Individualinteressen, behaupten konnte. Eben hier wirkt die Senatsaristokratie Roms mehr geeint als getrennt.

Wie sich nach 395 der „bessere Teil der Menschheit“, die pars melior humani generis $^{8}$, politisch und gesellschaftlich positionierte, welche Bedeutung ihm beizumessen ist und wie er sein Überleben sichern konnte, sind die zentralen Fragen dieser Arbeit. Es wird hierbei erforderlich, sich von den alten Narrativen einer moralisierenden Geschichtsbetrachtung ${ }^{9}$ zu lösen, die in der Senatsaristokratie nur Dekadenz, Eigennutz und Untätigkeit erkennen wollten. Zugleich ist die Fokussierung auf die

5 Vgl. etwa DEMANDT (2008) 264.

6 Vgl. STICKLER (2002) 285 und BARNISH (1988) 141.

7 Vgl. STICKLER (2002) 280.

8 Symm. ep. 1,52.

9 Hiergegen hat sich jüngst auch MEURER (2019) 3-8 positioniert. 
Geschichte der Kaiser und Heermeister, wie sie die Spätantikenforschung stark prägt, ${ }^{10}$ aufzuheben. Dabei soll für die erste Hälfte des 5. Jhs. nicht nur eine politische Geschichte des weströmischen Senats und der stadtrömischen Senatsaristokratie vorgelegt werden, wie sie seit Längerem schon gefordert wird. ${ }^{11}$ Darüber hinaus wird der Forschungsgegenstand dieser Arbeit, die stadtrömische Senatsaristokratie, den Ausgangs- und Ankerpunkt für ein Panorama darstellen, welches in der Breite der behandelten Themenfelder sowohl für die Geschichte der Stadt Rom und die Sozialgeschichte der Spätantike als auch für das Verstehen der Christianisierung des Weströmischen Reiches eine Bereicherung darstellen wird.

So beabsichtigt die hier vorgelegte Studie, ältere und jüngere Forschungsfelder und Beiträge zusammenzuführen, aktuelle Diskussionen zu erschließen und unter der gewählten Fokussierung neue Akzente zu setzen. Die Arbeit folgt hierbei einem stark ausgeprägten interdisziplinären Ansatz, der neben den klassischen althistorischen Quellen, den literarischen, epigraphischen und numismatischen Zeugnissen, im Besonderen den archäologischen Befund einbezieht und historisch kontextualisiert auswertet. Damit wird für die althistorische Forschung das in den letzten Jahrzehnten stark expandierende Feld der spätantiken und christlichen Archäologie erschlossen und für sozialgeschichtliche Fragestellungen, die im Zusammenhang mit der stadtrömischen Senatsaristokratie stehen, fruchtbar gemach

10 Unter den neueren Forschungsarbeiten zu den spätantiken Heermeistern: ANDERS (2010); JANSSEN (2004); MACGEORGE (2002); STICKLER (2002); COULON (2000) und LÜTKENHAUS (1998). Zu JANSSEN vgl. auch die eher kritische Rezension STICKLER, In: Sehepunkte 5 (2005) Nr. 6, 15.06.2005. Gesamtdarstellungen, die vor allem die Kaiser und Heermeister in den Blick nehmen: z. B. PFEILSCHIFTER (2014) oder BÖRM (2013).

11 U. a. STICKLER (2002) 273f.; SCHLINKERT (1996a), 23 Anm. 54; MARTIN 2(1990) 190 und ECK, Rez. Gnomon 46 (1974) 681: „Eine adäquate Behandlung der spätantiken Senatsaristokratie bleibt weiterhin ein Desiderat der Forschung.“ 